University of Nebraska - Lincoln

DigitalCommons@University of Nebraska - Lincoln

Faculty Publications: Department of Entomology

2004

\title{
Flight Muscle-Specific Expression of act88F: GFP in Transgenic Culex quinquefasciatus Say (Diptera: Culicidae)
}

Margaret L. Allen

University of California, Riverside, mallen2@unl.edu

Bruce M. Christensen

University of Wisconsin, Madison

Follow this and additional works at: https://digitalcommons.unl.edu/entomologyfacpub

Part of the Entomology Commons

Allen, Margaret L. and Christensen, Bruce M., "Flight Muscle-Specific Expression of act88F: GFP in Transgenic Culex quinquefasciatus Say (Diptera: Culicidae)" (2004). Faculty Publications: Department of Entomology. 440.

https://digitalcommons.unl.edu/entomologyfacpub/440

This Article is brought to you for free and open access by the Entomology, Department of at DigitalCommons@University of Nebraska - Lincoln. It has been accepted for inclusion in Faculty Publications: Department of Entomology by an authorized administrator of DigitalCommons@University of Nebraska - Lincoln. 
Published in Parasitology International 53 (2004), pp. 307-314; doi: 10.1016/j.parint.2004.04.002. Copyright (C) 2004 Elsevier Ireland Ltd. Used by permission.

Submitted October 14, 2003; accepted April 14, 2004; published online August 4, 2004.

Work was performed at University of California, Riverside, CA, USA

\title{
Flight Muscle-Specific Expression of act88F: GFP in Transgenic Culex quinquefasciatus Say (Diptera: Culicidae)
}

\author{
Margaret L. Allen ${ }^{1}$ and Bruce M. Christensen ${ }^{2}$
}

1. Entomology Department, University of California, Riverside, CA 92521, USA

2. Department of Animal Health and Biomedical Sciences, University of Wisconsin, Madison, WI 53706, USA

Corresponding author - Margaret L. Allen, USDA-ARS MLIRU, 305 Plant Industries Bldg., UNL-East, Lincoln, NE 68583, USA, telephone 402-472-5039, email mallen2@unl.edu

\begin{abstract}
A strategy to engineer a strain of Culex mosquitoes refractory to filarial transmission is described. A requirement for success of the strategy is identification of a flight musclespecific promoter that functions in the mosquito. A GFP marker gene under the control of the promoter region of the Drosophila melanogaster act88F gene was inserted into the genome of Culex quinquefasciatus. Transformation was confirmed by Mendelian genetics. Hybridization of a genomic Southern blot to a radiolabeled probe verified that the entire donor plasmid integrated into the mosquito genome. GFP expression in the transgenic mosquitoes was restricted to the flight muscles.
\end{abstract}

Keywords: Culex quinquefasciatus, mosquito, filariasis, actin; Hermes, germ-line transformation, green fluorescent protein (GFP)

Abbreviations: green fluorescent protein (GFP); ultraviolet (UV); transposable element (TE) 


\section{Introduction}

Culex quinquefasciatus Say is the most important mosquito vector for urban human lymphatic filariasis, caused by infection with the parasitic nematode Wuchereria bancrofti. Lymphatic filariasis infects some 120 million people worldwide. The nematode completes its lifecycle by undergoing two molts, from 1st- to 3rd-stage infective larvae, in the flight muscles of the adult mosquito [1,2]. The mosquito ingests the microfilariae when it takes a blood meal from an infected human. The microfilariae burrow through the gut tissues of the mosquito and migrate through the hemocoel into the thoracic muscle cells within about $8 \mathrm{~h}$. This occurs in both susceptible mosquitoes (those in which the parasite completes development to the infective stage) and often in refractory mosquitoes (those in which it does not) $[3,4]$, suggesting some process occurs in the flight muscle cells of refractory mosquitoes that interferes with development of the nematodes. The nature of this process, and the associated compounds and genetic factors, have yet to be identified.

Within the past 4 years, transgenic insect technology has become a viable research tool $[5,6]$, and novel genetic mosquito control systems incorporating mosquito transformation have been proposed and tested in mosquitoes [7-11]. We now propose a transgenic control system in the lymphatic filariasis vector, $C x$. quinquefasciatus.

A transgenic system that incorporates an anti-filarial effector gene under the control of a flight muscle-specific promoter could result in a mosquito engineered to be refractory to filarial development. This system would require:

1. an effective method for producing transgenic mosquitoes;

2. a promoter that would drive expression specifically in flight muscles; and

3. an effector gene that would produce a molecule toxic or inhibitory to filarial development. As an additional requirement, the strain of mosquito used for testing this project would have to be a competent (susceptible) host for W. bancrofti in its wild-type state. The research described here demonstrates feasibility for the first two requirements of this strategy.

Act88F is a Drosophila melanogaster flight muscle-specific gene that encodes an isoform of actin [12-15], and has been studied in some detail in D. melanogaster [16]. The promoter region of the act88F gene has been cloned and demonstrated to produce tissue-specific expression in D. melanogaster [17]. No actin genes have been cloned from $C x$. quinquefasciatus or any other mosquito in the genus Culex.

The aim of this research was to identify a suitable promoter to drive expression in flight muscles of $C x$. quinquefasciatus. If the $D$. melanogaster act88F promoter region drives flight muscle-specific expression in $C x$. quinquefasciatus, the requirement for a flight muscle-specific promoter, as part of the strategy outlined above, is met. To achieve this, a transgenic line of $C x$. quinquefasciatus was produced utilizing a Hermes transposable element (TE) based transformation system. This system consisted of a Hermes transposase-coding helper plasmid and a Hermes donor plasmid incorporating a green fluorescent protein (GFP) coding sequence under the control of the act88F promoter and flanked by Hermes TE ends. 


\section{Materials and methods}

\subsection{Production of transgenic insects}

Freshly laid wild-type mosquito eggs were collected from existing colonies and microinjected as described [18]. Embryos were heat shocked at $8 \mathrm{~h}$ development for $30 \mathrm{~min}$ in a $40^{\circ} \mathrm{C}$ incubator. Surviving mosquitoes $\left(\mathrm{G}_{0}\right)$ were reared and mated to wild-type in individual cages for males, and pooled females. Egg rafts produced by these matings were isolated and reared to pupation. Pupae were screened twice by visual examination using UV illumination with a Leica MZ12 stereomicroscope and Leica fluorescence module. Pupae were screened when first collected and again after 12-24 h. Those that expressed GFP (G1 putative transgenics) were isolated and mated to wild-type specimens. Egg rafts produced by these matings were again isolated and reared to pupation, screened for GFP expression, and counted to determine ratios of GFP-expressing progeny. From two of the six fertile $\mathrm{G}_{1}$ matings $\mathrm{GFP}+$ progeny $\left(\mathrm{G}_{2}\right)$ were reared and sib-mated. The progeny of these two matings were again screened to determine ratios of GFP-expressing progeny, and used to found two colonies, identified as "Rud" and "Yard." Specimens from subsequent generations were continually screened to remove genetically wild-type offspring, and sacrificed for photography and DNA extraction as quantities became available.

\subsection{Establishment of homozygous transgenic Hermes[act88:GFP] line}

Pupae were collected from the colony rearing tray and sexed. Those insects not expressing the GFP were discarded. Twenty male pupae were isolated and allowed to eclose as adults, and were visually inspected as adults to verify sex. Twenty of the most brightly fluorescing female pupae were also isolated and verified as adults, and all 40 adults were placed in a mating cage. Females were provided with a blood meal and allowed to oviposit. Six egg rafts were collected and reared in isolation. Upon pupation, insects were screened for GFP fluorescence. Those rafts found to contain only GFP+ males were used to found the homozygous colony.

\subsection{Sex linkage}

Male pupae from each of the two transgenic colonies were isolated and mated to wild-type females. Twenty of each sex were placed in each cage, in which females were blood-fed and allowed to oviposit. Egg rafts were collected and four rafts from each cage were isolated and reared to pupation. Pupae were screened for GFP expression and sex, and counted to determine sex-linkage ratios.

\subsection{Persistence of marker expression}

Female transgenic specimens were collected as pupae and examined at 1 day, 14 days, and 30 days post adult eclosion. Specimens were examined whole and dissected using the UV stereomicroscope described above.

\subsection{Plasmids}

The plasmids used were a donor, pBSHermes[88:gfp], and a Hermes transposase-encoding helper, pHSHH1.9 [19]. Equal amounts of donor and helper plasmid were suspended in 
injection buffer [20] at a total DNA concentration of $250 \mathrm{ng} / \mu \mathrm{l}$. Blue food dye (Durkee) was included in the plasmid injection solution at a concentration of $1 / 100 \mu \mathrm{l}$.

\subsection{DNA Hybridization}

Genomic DNA was extracted from pupae of each transgenic colony and from the wild type colony, in pools of 8 individuals, using Promega Wizard kits and according to instructions (for "rat tail") provided by the manufacturer. Extractions were pooled and quantitated spectrophotometrically. Donor plasmid DNA was prepared using Qiagen Endotoxin-free Midi-prep kits and also quantitated. Plasmid and genomic DNA were digested with the following enzymes: EcoRI, SacI, XbaI. Double enzyme digests were prepared using EcoRI + $\mathrm{XbaI}$. Plasmid DNA was digested in volumes of $40 \mu \mathrm{l}$, and specimens were diluted to 100 pg in $20 \mu \mathrm{l}$ for Southern blotting. Genomic DNA specimens were digested overnight in volumes of $400 \mu \mathrm{l}$, and containing $10 \mu \mathrm{g}$ of wild-type genomic DNA per digest and $4 \mu \mathrm{g}$ of transgenic genomic DNA per digest. Wild-type genomic DNA was digested with EcoRI only (as a negative control). Digested DNA samples of plasmid DNA, wild-type genomic DNA, and transgenic genomic DNA were size fractionated by electrophoresis in $0.8 \%$ $(\mathrm{w} / \mathrm{v})$ agarose, and Southern blot transfer and hybridizations were performed using standard procedures [21]. Probe was prepared using Amersham Pharmacia Biotech Rediprime II random prime labeling kit according to instructions provided.

\section{Results}

\subsection{Generation and genetic verification of Hermes[act88:GFP] transgenic Culex quin- quefasciatus}

Of 185 injected and heat-shocked embryos, 69 were recorded as embryonated after $24 \mathrm{~h}$. In a normally developing embryo at this stage, red eyespots or stemmata are visible, and those injected embryos with stemmata were scored as embryonated. After $55 \mathrm{~h}$, injected embryos were again examined, and empty eggshells were counted as hatched. By this definition 64 hatched embryos were identified. At each embryo examination, the injected embryos were examined with UV illumination for GFP expression, and at no time was expression observed in developing embryos. All surviving larvae were examined $(n=50)$ on day 4 , and no GFP expression was detected. As larvae pupated they were again screened for GFP expression, and again none was detected. Thirty-seven survived to the adult stage, or $20 \%$ of the total number of injected embryos. From these, 32 fertile matings yielded 7352 pupae, which were screened for GFP expression. Two egg rafts, both from the female pool, produced GFP+ pupae. From one egg raft, a single GFP+ pupa was collected and allowed to emerge. It was female and was provided with wild-type males and blood-fed repeatedly, but produced few eggs. The eggs that hatched died prior to completing larval development. From the other egg raft, six GFP+ pupae were collected. All were fertile females and produced GFP+ progeny in $50 \%$ ratios expected from a single locus insertion of a dominant allele. Two of the cohorts, rafts $1 \& 6$, were kept to found colonies, designated Rud and Yard, and four were discarded. The siblings in the cohorts that did not express GFP were discarded, and the remaining siblings were mated together. These siblings represented the second transgenic generation, G2. Assuming that each of the mated siblings was 
heterozygous for the dominant $g f p$ marker, Mendelian inheritance would predict 1:2:1 ratios of homozygous GFP+ to heterozygous GFP+ to wild-type, respectively. The expected ratios were observed (table 1). Two additional observations were made during these screenings: more of the early pupating siblings in a cohort appeared to be the wild-type phenotype, and some of the later-pupating siblings seemed to vary in the intensity of fluorescence. Embryos injected with donor plasmid only did not produce transgenics, as expected, based on previous experimentation [18].

Table 1. Inheritance of GFP marker in transgenic $C x$. quinquefasciatus pupae; second transgenic generation ( $\mathrm{G}_{2}$ progeny). GFP+ siblings were pool mated, and six representative egg rafts from each colony were reared and counted.

\begin{tabular}{lcccc}
\hline Raft & Total pupae & GFP+ & Expected & Ratio (\%) \\
\hline A. Colony “Rud” & & & & \\
1 & 168 & 120 & 126 & 71.4 \\
2 & 158 & 121 & 118.5 & 76.6 \\
3 & 181 & 143 & 135.75 & 79.0 \\
4 & 229 & 171 & 171.75 & 74.7 \\
5 & 199 & 143 & 149.25 & 71.9 \\
6 & 194 & 141 & 145.5 & 72.7 \\
Total & 1129 & 839 & 846.75 & 74.3 \\
Average & 188.17 & 139.83 & & 74.4 \\
Std. Dev. & 25.25 & 18.66 & & 3.0 \\
$\chi^{2}$ df 1 (expected 75\% GFP+) & $0.284, P>0.5$ & & & \\
B. Colony “Yard” & & & & \\
1 & 165 & 127 & 123.75 & 77.0 \\
2 & 180 & 144 & 135 & 80.0 \\
3 & 177 & 143 & 132.75 & 80.8 \\
4 & 215 & 151 & 161.25 & 70.2 \\
5 & 196 & 147 & 147 & 75.0 \\
6 & 186 & 127 & 139.5 & 68.3 \\
Total & 1119 & 839 & 839.25 & 75.0 \\
Average & 186.5 & 139.83 & & 75.2 \\
$\chi^{2}$ df $=1$ (expected 75\% GFP+) & $0.001, P>0.9$ & 10.32 & & \\
\hline & & & & \\
\hline
\end{tabular}

Fluorescence was visible in the pupal thorax, as shown in figure 1a-d. In figure $1 \mathrm{~b}$ large muscle masses, which nearly fill the thoracic area, are clearly visible. The indirect flight muscles (IFMs) are composed of roughly perpendicular sets of oblique lateral dorsal muscles (dorsolateral) and tergosternal muscles (dorsoventral) [22]. Figure 1c shows a dorsal view of the pupa in which fluorescent muscle masses are visible; these are elongated from anterior to posterior. The proportions and positions of the fluorescent muscle masses are strikingly similar to those shown in act88F:GFP transformed D. melanogaster mature pupae [17]. When late larval instar specimens were examined, some fluorescence was detected in 
what are clearly pharate pupae; in figure 1d developing respiratory trumpets (a morphological characteristic of the mosquito pupa) are apparent. The muscles in the thorax are beginning to form, but not yet elongated. Developmentally prior to this expression in the pharate pupa, no fluorescence was detected in any embryo or larva examined. Fluorescence is visible throughout the interior of the adult thorax (fig. 1e). These patterns of fluorescence expression correspond to expression described in D. melanogaster act88F:GFP transformants [17].

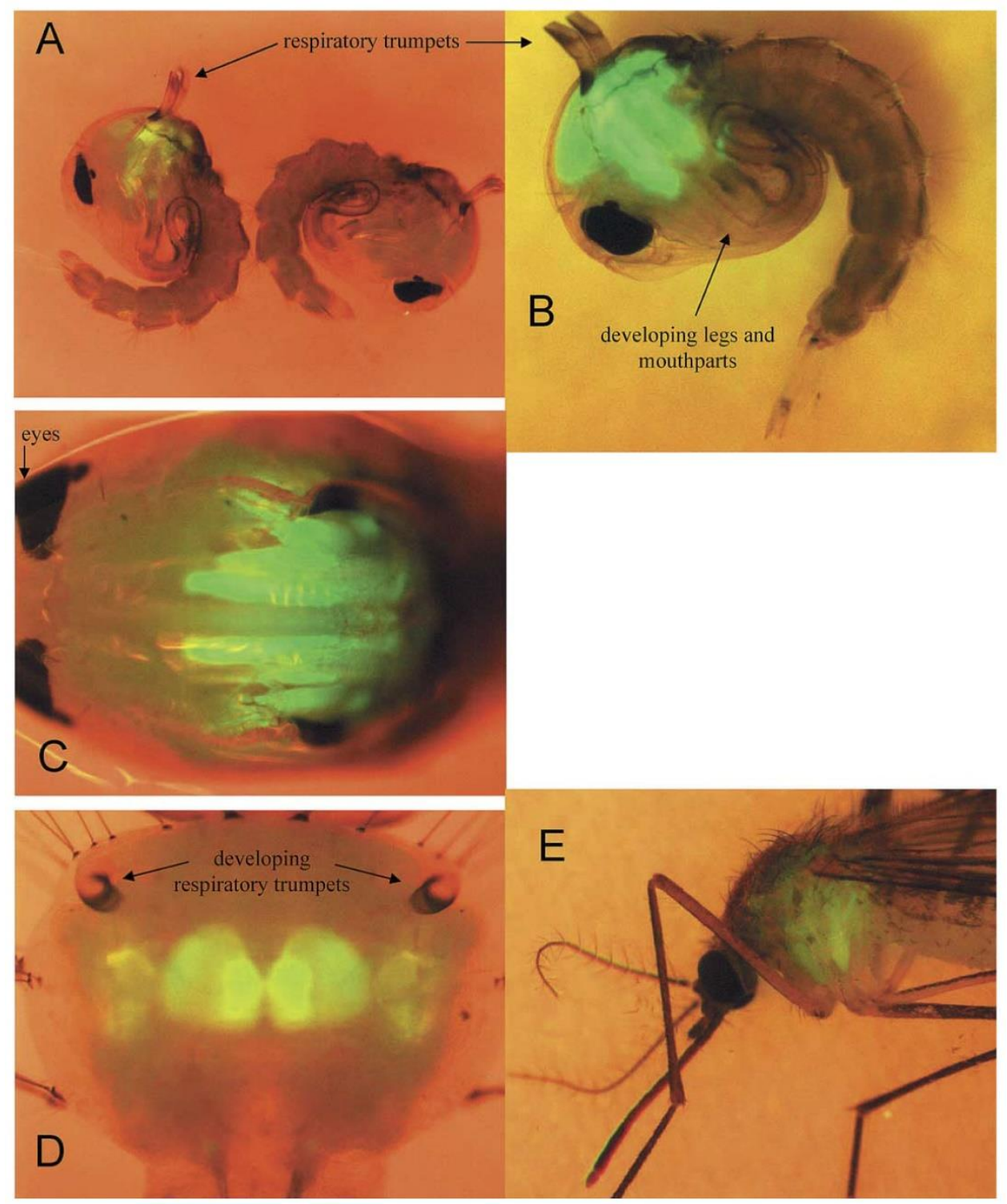

Figure 1. Transgenic Culex quinquefasciatus Say. a-d: pupae (a) males; transgenic on left, wild-type on the right. (b) homozygous female (c) dorsal view (d) pharate (e) adult. 


\subsection{Analysis of Southern blot hybridization}

Restriction enzyme digests of donor plasmid, wild-type genomic $C x$. quinquefasciatus DNA, and genomic DNA from both transgenic colonies were hybridized with radio-labeled probe DNA made from the entire donor plasmid (fig. 2). In other Hermes transgenic mosquitoes, both the Hermes element and flanking plasmid DNA have been shown to integrate into the genome $[18,23]$. The entire donor plasmid was radiolabeled and used for hybridization so that integrations such as those found in previously transformed mosquitoes could be clearly identified. Wild-type genomic $C x$. quinquefasciatus DNA did not hybridize with the probe. This indicates that the wild-type $C x$. quinquefasciatus genome does not include sequences of sufficient homology to those of the donor plasmid to permit hybridization under the high stringency conditions used. The patterns of hybridization seen in the two transgenic colony samples (Rud and Yard) are identical. This indicates that the two colonies have identical genomic transgene integration. Since the probe would be expected to hybridize to both sides of each integration site, each integration should be represented by a pair of bands of hybridization. The XbaI digestion produced hybridization of restriction fragments that were too large to differentiate, indicating that the genomic $\mathrm{XbaI}$ restriction sites were all distant from integrations. Digestion with EcoRI and SacI Double digestion show multiple germ-line integrations. Double digestion with XbaI and EcoRI yielded one expected hybridization band approximately $2.5 \mathrm{~kb}$ smaller than the EcoRI band at around $7.5 \mathrm{~kb}$, which would be predicted from the restriction map (fig. 2). 

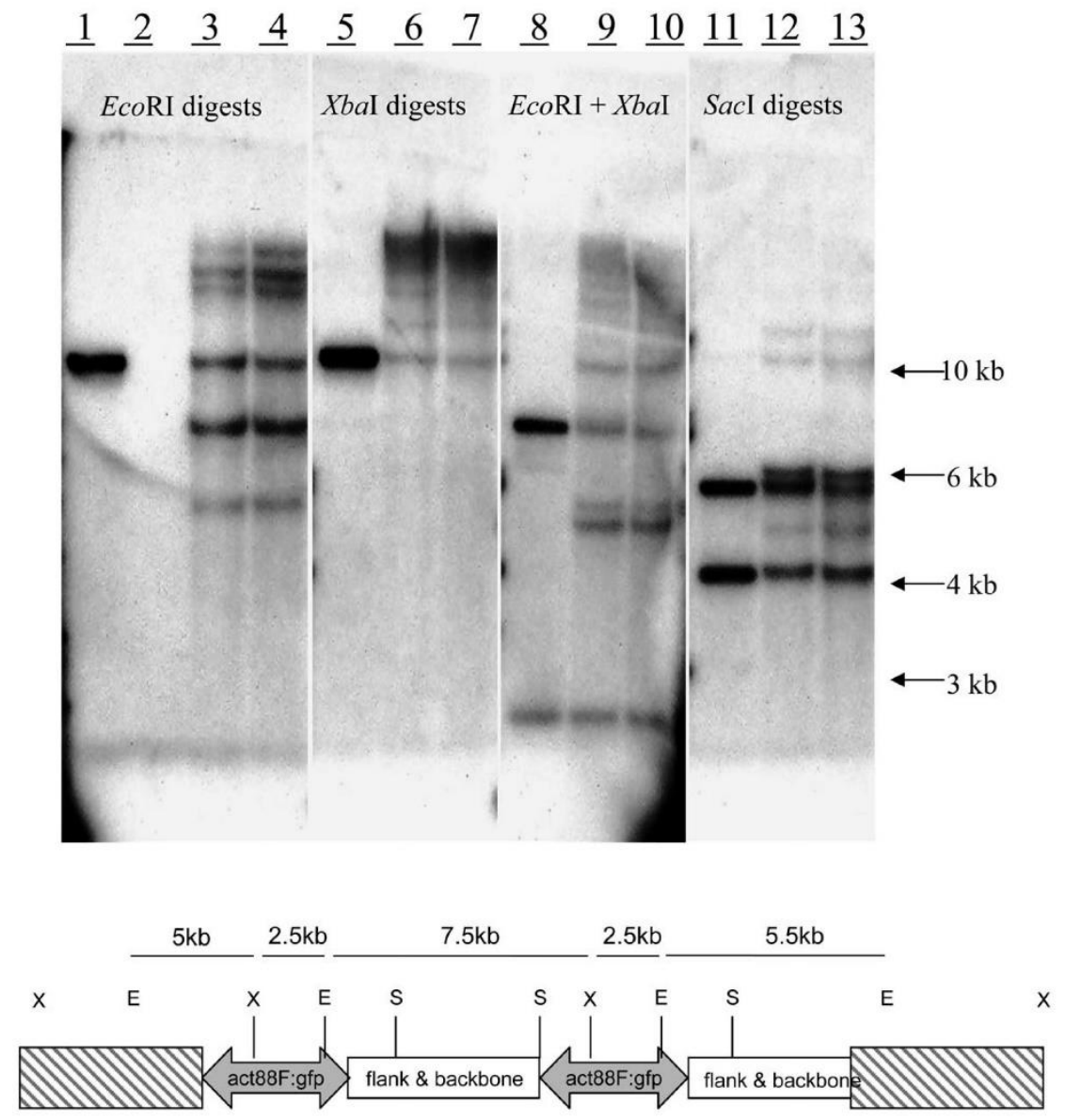

Figure 2. Above: DNA hybridization of donor plasmid probe to digested genomic $C x$. quinquefasciatus DNA. Lanes 1,5,8,11: plasmid pHermes[Act88:GFP]. Lane 2: wild-type Cx. quinquefasciatus genomic DNA. Lanes 3,6,9,12: transgenic Cx. quinquefasciatus genomic DNA from Rud colony. Lanes 4,7,10,13: transgenic Cx. quinquefasciatus genomic DNA from Yard colony. Below: schematic representation of proposed integration. Restriction enzyme sites are: X: XbaI, E: EcoRI, S: SacI. Diagonally slashed boxes represent Cx. quinquefasciatus genome DNA.

\subsection{Determination of sex-linkage}

Because sex is determined in Culex by a dominant male locus $M$ [24], a simple way to test for sex-linkage of the transgene was to cross GFP+ males with wild-type females. The expected outcome of this cross would be all GFP+ females, and all wild-type males. This test was performed for both lines, and of the four rafts screened for each colony cross, expected ratios were recorded consistently (table 2). 
Table 2. Ratios of GFP+ males and females resulting from crossing wild-type females with transgenic males, from colonies indicated, to demonstrate sex linkage

\begin{tabular}{lccccccc}
\hline Colony & Raft & $\begin{array}{c}\text { Male } \\
\text { GFP+ }\end{array}$ & $\begin{array}{c}\text { Male } \\
\mathrm{wt}\end{array}$ & $\begin{array}{c}\text { Male } \\
\% \text { GFP+ }\end{array}$ & $\begin{array}{c}\text { Female } \\
\text { GFP+ }\end{array}$ & $\begin{array}{c}\text { Female } \\
\text { wt }\end{array}$ & $\begin{array}{c}\text { Female } \\
\% \text { GFP+ }\end{array}$ \\
\hline Yard & 1 & 0 & 100 & $0 \%$ & 118 & 0 & $100 \%$ \\
Yard & 2 & 0 & 95 & $0 \%$ & 103 & 0 & $100 \%$ \\
Yard & 3 & 0 & 134 & $0 \%$ & 116 & 0 & $100 \%$ \\
Yard & 4 & 0 & 87 & $0 \%$ & 85 & 0 & $100 \%$ \\
Rud & 1 & 0 & 79 & $0 \%$ & 72 & 0 & $100 \%$ \\
Rud & 2 & 0 & 99 & $0 \%$ & 112 & 0 & $100 \%$ \\
Rud & 3 & 0 & 88 & $0 \%$ & 108 & 0 & $100 \%$ \\
Rud & 4 & 0 & 78 & $0 \%$ & 95 & 0 & $100 \%$ \\
& & & & Male $\%$ & & & Female $\%$ \\
Total Rud & & 0 & 344 & $47.1 \%$ & 387 & 0 & $52.9 \%$ \\
Total Yard & & 0 & 416 & $49.6 \%$ & 422 & 0 & $50.4 \%$ \\
Overall total & & 0 & 760 & $48.4 \%$ & 809 & 0 & $51.6 \%$ \\
\hline
\end{tabular}

\subsection{Persistence of GFP expression}

Adult specimens were examined to determine whether GFP continued to be evident during the imaginal stage. At 1 day and 14 days after imaginal eclosion, adult specimens were dissected and photographed. Whole adults were also examined, and a photograph of the last surviving adult at 30 days post-eclosion is presented in figure 1e. All of the adults examined showed distinct green fluorescence.

\section{Discussion}

An early indication of successful microinjection of the specimens was a high percentage of embryonation in the injected embryos. Many of the embryos did not survive larval development, but the $20 \%$ survival to the imaginal stage and $17.3 \%$ fertility shown here are comparable to previous Culex transgenic production [18] in which a total of 28 surviving adults and 17 fertile adults were produced from a total of 122 injected embryos $(23.0 \%$ and $13.9 \%$, respectively). In the previous transgenic experiments there was no easily visible differentiation between homozygous and heterozygous expression as has been reported here. Furthermore, this is the first report of a sex-linked transgenic $C x$. quinquefasciatus line. It should be possible to clone sex-related genes from this species genome utilizing the inserted plasmid and marker DNA. It may be necessary to utilize large-scale cloning procedures to accomplish this, such as creating chromosome jumping libraries, since there may be several hundred kilobases of genomic DNA defining the locus associated with sex inheritance.

An unanticipated benefit of the sex-linked insertion was the ease of producing a homozygous line. Due to space requirements dictated by $C x$. quinquefasciatus biology, specifically cage size needed for mating and blood-feeding, individual pair matings present a problem. Because transgenic animals could only participate in two possible crosses, the option existed of screening males, which conveniently pupate first in any given cohort. If 
a GFP+ male mates with a heterozygous GFP+ female $(\mathrm{MmG} \times \mathrm{mmG}), 50 \%$ of the male progeny should be wild-type. If the female is homozygous ( $\mathrm{mcmG}$ ), all of the progeny should be GFP+. Once a sufficient number of male pupae were screened, the genetic status of remaining siblings could be predicted with high certainty.

Limitations on rearing facilities necessitated the decision to rear only two of the six possible transgenic founder colonies $\left(\mathrm{G}_{2}\right)$. Thus one cannot know for sure that the six $\mathrm{G}_{1}$ specimens isolated from a single Go parent represented a single insertion event. The results showing that both transgenic colonies had sex-linked transgenes, in addition to the identical patterns of hybridization in the Southern blot indicate that these two colonies represent the same transgenic event. It is also most likely that all six siblings contained identical donor inserts.

The most important conclusion from this experiment is the functional conservation of D. melanogaster act88F promoter in Cx. quinquefasciatus. The promoter region of the D. melanogaster act $88 \mathrm{~F}$ drives GFP expression in the indirect flight muscles of D. melanogaster [17]. However, this was no guarantee that the promoter would drive equivalent expression in a distantly related member of the order Diptera, such as $C x$. quinquefasciatus. A dorsal view of the fluorescence of the developing flight muscles in our transgenics (fig. 1c) show dramatic similarity to the fluorescence micrographs presented in Barthmaier and Fyrberg (1995), appearing as four distinct masses.

Actins are major contractile and structural proteins found in muscle and other cells. They are a family of closely homologous isoforms, and each isoform has distinct functional importance. Multicellular organisms usually have multiple highly conserved genes coding for different actin isoforms. For example, bird and mammal genomes contain eight different, tissue-specific actin isoforms $[25,26]$. Six actin genes are present in D. melanogaster and are closely homologous to each other in coding regions but not in untranslated or flanking regions. The actin proteins encoded by these genes were more closely homologous to vertebrate cytoplasmic isoforms than to vertebrate muscle isoforms [27]. Actin genes have recently been identified from Ae. Aegypti [28] and from Mayetiola destructor [29]. The protein and nucleic acid coding sequences of these actins are highly homologous to D. melanogaster actins (approx. 95\% and 89\%, respectively) but promoter regions have not yet been isolated, and hence have not been compared. Comparison of the D. melanogaster actin88F sequence (genomic sequence AB003910) to the sequenced Anopheles gambiae genome results in seven homologous BLAST hits, which correspond to loci on the $X, 2$, and 3 chromosomes. These homologous genes are similar to the actin $88 \mathrm{~F}$ nucleotides between 2700 and 4000 , not to the $5^{\prime}$ gene region. A comparison of the $5^{\prime}$ flank sequence of the actin $88 \mathrm{~F}$ (genomic sequence M13925) results in no significant homology [30].

Other D. melanogaster promoters used in transgenic $C x$. quinquefasciatus studies have included another actin promoter, $a c t 5 C$, and the heat shock promoter $h s p 70$ [18]. The cinnabar gene, including promoter region, was used as a promoter-marker construct to transform Ae. aegypti, and functioned to rescue eye color in the white-eyed mosquito strain [31,32]. The results presented here add to the list of useful D. melanogaster promoter regions that can be used in mosquitoes, and possibly other heterologous insects.

If the act $88 \mathrm{~F}$ promoter region were utilized in the development of a filariasis-resistant strain of $C x$. quinquefasciatus, it would be useful to know whether an effector gene under 
the control of this promoter would be produced throughout the adult lifetime of the female mosquito. Our observations of the GFP expression throughout the adult stage of our transgenics were designed to give us this indication. GFP was clearly visible in the thorax, even through the adult cuticle, throughout the lifetime of adults (fig. 1e). Whether this is a reliable indication of continued transcription and translation of the gfp gene is not clear strictly from this observation. The protein or mRNA itself may persist in vivo. The half-life of enhanced green fluorescent protein (EGFP), as stated by Clontech (http://www.clontech.com/ techinfo/faqs/GFPTechTip.shtml) is $24 \mathrm{~h}$. Therefore, degradation of the protein would be expected over a course of 30 days, if expression were temporally restricted to the pupal stage. This did not appear to occur, so either the protein is not degraded as expected, or it is replenished during the adult lifespan. If a putative antimicrofilaria-coding gene were incorporated into a transgenic mosquito, further research including RNA studies to verify transcriptional activity in aging female mosquitoes would be necessary.

There are unanswered questions associated with this transformation method. Why does the Hermes system produce transgenic mosquitoes $[18,23]$ with replicated copies of the entire donor plasmid integrated into the genome? Host factors involved in integration in mosquitoes have been proposed [18], but none have been identified. Host factors play regulatory roles in other TE systems, such as the flamenco gene with the gypsy element, Inverse Repeat Binding Protein (IRBP) and $P$ element Somatic Inhibitor (PSI) with the $P$ element, or methylation phenomena in the Tad and Spm elements [33]. What are the characteristics of the genomic locations into which Hermes inserts? The replicative nature of the genomic integrations confounds efforts to clearly identify and characterize the integration junctions.

Acknowledgments - Cynthia S. LeVesque provided the expertise responsible for generation of the clear and readable Southern blot data presented here; John Peloquin provided critical advice on analysis of the Southern. The inspiration and for the concept of a filarial resistant strain of Cx. quinquefasciatus came from conversations with Carl A. Lowenberger and Prakash Srinivasan. Consultation and encouragement were also provided by Lyric Bartholomay. Insect rearing and maintenance assistance was provided by Regina Foreman, Sunny Soun, Stephanie Hung, Amber Quilitian, and Mary Klein. This work was supported by the University of California Systemwide Mosquito Research Program. This paper is No. 13908 of the Journal Series of the University of Nebraska Agricultural Research Division and Contribution no. 1140 of the Department of Entomology, University of Nebraska Lincoln.

\section{References}

[1] Despommier DD, Karapelou JW, Gwardz RW, Hotez PJ, Knirsch CA, Miller LH. Parasitic diseases. New York: Apple Trees Productions, 2000.

[2] Michael E, Bundy DA, Grenfell BT. Parasitology 1996;112(Pt 4): 409-28.

[3] Omar MS, Zielke E. Tropenmed Parasitol 1978;29(3):364-70.

[4] Gad AM, Farid HA, Hammad RE, Hussein MA, Kaschef AH. J Egypt Soc Parasitol 1996;26(1):93104.

[5] Moreira LA, Ghosh AK, Abraham EG, Jacobs-Lorena M. Int J Parasitol 2002;32(13):1599-605.

[6] Coluzzi M, Costantini C. Parassitologia 2002;44(3-4):131-35.

[7] Adelman ZN, Jasinskiene N, James AA. Mol Biochem Parasitol 2002;121(1):1-10. 
[8] Moreira LA, Edwards MJ, Adhami F, Jasinskiene N, James AA, Jacobs-Lorena M. Proc Natl Acad Sci USA 2000;97(20):10895-98.

[9] Moreira LA, Ito J, Ghosh A, Devenport M, Zieler H, Abraham EG, et al. J Biol Chem 2002;277(43):40839-43.

[10] Kokoza V, Ahmed A, Cho WL, Jasinskiene N, James AA, Raikhel A. Proc Natl Acad Sci USA 2000;97(16):9144-49.

[11] Blair CD, Adelman ZN, Olson KE. Clin Microbiol Rev 2000; 13(4):651-61.

[12] Fyrberg EA, Mahaffey JW, Bond BJ, Davidson N. Cell 1983; 33(1):115-23.

[13] Sanchez F, Tobin SL, Rdest U, Zulauf E, McCarthy BJ. J Mol Biol 1983;163(4):533-51.

[14] Tobin SL, Zulauf E, Sanchez F, Craig EA, McCarthy BJ. Cell 1980;19:121-31.

[15] Fyrberg EA, Kindle KL, Davidson N. Cell 1980;19(2):365-78.

[16] Fyrberg EA, Fyrberg CC, Biggs JR, Saville D, Beall CJ, Ketchum A. Biochem Genet 1998;36(78):271-87.

[17] Barthmaier P, Fyrberg E. Dev Biol 1995;169(2):770-74.

[18] Allen ML, O'Brochta DA, Atkinson PW, Levesque CS. J Med Entomol 2001;38(5):701-10.

[19] Sarkar A, Coates CJ, Whyard S, Willhoeft U, Atkinson PW, O'Brochta DA. Genetica 1997;99(1): 15-29.

[20] Rubin GM, Spradling AC. Science 1982;218(4570):348-53.

[21] Sambrook J, Maniatis T, Fritsch EF. Molecular cloning: a laboratory manual. Cold Spring Harbor, NY: Cold Spring Harbor Laboratory, 1989.

[22] Snodgrass RE. Principles of insect morphology. New York: McGraw-Hill Book Company, 1935.

[23] Jasinskiene N, Coates CJ, James AA. Insect Mol Biol 2000;9(1): 11-18.

[24] Gilchrist BM, Haldane JBS. Hereditas 1947;33:175-90.

[25] Mounier N, Sparrow JC. J Mol Evol 1997;44(1):89-97.

[26] Rubenstein PA. Bioessays 1990;12(7):309-15.

[27] Fyrberg EA, Bond BJ, Hershey ND, Mixter KS, Davidson N. Cell 1981;24(1):107-16.

[28] Ibrahim MS, Eisinger SW, Scott AL. J Med Entomol 1996; 33(6):955-62.

[29] Shukle RH. Annals of the Entomological Society of America 2000;93(5):1164-72.

[30] Altschul SF, Gish W, Miller W, Myers EW, Lipman DJ. J Mol Biol 1990;215(3):403-10.

[31] Jasinskiene N, Coates CJ, Benedict MQ, Cornel AJ, Rafferty CS, James AA. Proc Natl Acad Sci USA 1998;95(7):3743-47.

[32] Lobo NF, Hua-Van A, Li X, Nolen BM , Fraser MJ Jr. Insect Mol Biol 2002;11(2):133-39.

[33] Capy P. Dynamics and evolution of transposable elements. Austin, Texas \& New York: Landes Bioscience; North American distributor Chapman \& Hall, 1998. 